\title{
Clinical profile and treatment outcomes of metastatic neuroendocrine carcinoma: A single institution experience
}

\author{
K. N. Lokesh, Abhishek Anand, K. C. Lakshmaiah, K. Govind Babu, Dasappa Lokanatha, Linu Abraham Jacob, \\ M. C. Suresh Babu, A. H. Rudresha, L. K. Rajeev, Smitha C. Saldanha, G.V. Giri, Dipti Panwar', Deepak Koppaka, \\ Rajesh Patidar
}

\begin{abstract}
Background: Neuroendocrine carcinoma (NEC) is a rare tumor arising from the diffuse neuroendocrine system. Most of these present in the advanced stage and palliative chemotherapy remains the only option. The prognosis remains poor with the standard chemotherapy regimen of platinum and etoposide (EP) providing modest survival benefit. Methods: The study was done for 3 years at a tertiary cancer center in South India. Patients with a diagnosis of metastatic NEC were analyzed for clinical and pathological characteristics. The treatment outcomes and prognostic factors were evaluated using appropriate statistical test. Results: A total of I 4 patients of metastatic NEC satisfied the inclusion criteria and were analyzed. Gastrointestinal including hepatobiliary tract (33\%) was the most common site of primary disease followed by lung (26\%), genitourinary (15\%), head and neck (I4\%), and unknown primary ( $9 \%$ ). On analysis of pattern of metastasis, liver (65\%) was the most common site followed by bone $(54 \%)$ and lung $(42 \%)$. The median overall survival was II months with a statistically significant difference between pulmonary and extrapulmonary disease ( 8 vs. I months; $P=0.003)$. Ki67\% value was strongly associated with prognosis (hazard ratio $0.517,95 \%$ confidence interval; $0.318-0.840, P=0.008$ ) whereas age, sex, and lactate dehydrogenase level did not show any relation with survival. Conclusion: The outcome of advanced NEC with standard chemotherapy remains poor. Larger studies with other therapeutic and novel agents are warranted to improve the treatment outcomes.
\end{abstract}

Key words: Ki67, neuroendocrine carcinoma, survival

\section{Introduction}

Neuroendocrine neoplasm (NEN) is a rare tumor arising from Kultchitzky cells or enterochromaffin cells present in the bronchial mucosa which is considered a part of the diffuse neuroendocrine system. ${ }^{[1-3]}$ The first description of neuroendocrine tumors (NETs) was given in 1904 by Siegfried Oberndorfer. ${ }^{[4]}$ These tumors can be present throughout the body. The most common site is small intestine $(30.4 \%)$ followed by lung $(29.8 \%){ }^{[5]}$ The extrapulmonary neuroendocrine carcinoma (EPNEC) occurs commonly in the esophagus, pancreas, periampullary region, and large bowel the grading system proposed by the World Health Organization classify NEN into three grades. ${ }^{[6]}$ The neuroendocrine tumor (NET; G1) have a mitotic count of $<2 / 10$ high-power fields (HPF) and/or a Ki67 index of $\leq 2 \%$. NET grade 2 has a mitotic count 2-10 per $10 \mathrm{HPF}$ and/or a Ki67 index between $3 \%$ and $20 \%$. The NEC which is grade 3 has a mitotic count of more than 20/10 HPF and/or a Ki67 index $>20 \%{ }^{[6]}$ The definition for lung and thymic NEN varies slightly with the cutoff for mitosis per $10 \mathrm{HPF}$ being $<2,2-10$, and $>10$ for low-, intermediate-, and high-grade neoplasm, respectively. The grade 3 NEC represents a poorly differentiated neoplasm previously classified as small cell carcinoma or poorly differentiated NEC (PDNEC). The incidence of NEC is rising mainly because of improved and precise pathological classification.

In comparison to NET, the PDNECs have an aggressive course and poor outcomes. Most of NEC patients present at an advanced stage with poor performance status and cannot be dealt with a curative surgery. ${ }^{[7,8]}$ Without chemotherapy, the median survival is dismal being only one month. ${ }^{[9]}$ Similar to extensive stage small cell lung cancer, platinum with etoposide (EP) regimen has been the standard therapy for

\begin{tabular}{|l|}
\hline Access this article online \\
\hline Quick Response Code: \\
\\
Website: www.sajc.org \\
\hline DOI: 10.4103/sajc.sajc_176_17 \\
\hline
\end{tabular}

Departments of Medical Oncology and 'Pathology, Kidwai Memorial Institute of Oncology, Bengaluru, Karnataka, India Correspondence to: Dr.Abhishek Anand, E-mail: drabhishek2508@gmail.com advanced NECs. ${ }^{[9,10]}$ Other therapeutic options for NECs include capecitabine, streptozotocin, 5-fluorouracil, doxorubicin, and temozolomide. ${ }^{[11-14]}$

We herein studied the clinicopathological profile and the treatment outcome of patients with advanced NECs from a single institution in South India.

\section{Methods}

It was a retrospective observational study of patients diagnosed with advanced NEC at the Department of Medical Oncology, Kidwai Cancer Institute. The study was done from January 2014 to December 2016. Those diagnosed with metastatic NEC of any site were evaluated for clinical and pathological characteristics. For diagnosis of NEC, immunohistochemistry report of synaptophysin, chromogranin positivity, and Ki67\% value of more than $20 \%$ (for lung tumor, Ki67 >10\%) were required. The response to treatment was observed according to the RECIST 1.1. Overall survival (OS) analysis was done using the Kaplan-Meier method. The association of different variables was analyzed using the log-rank test. Multivariate analysis was done to test the correlation of different factors (age, sex, lactate dehydrogenase [LDH], and Ki67\%) with survival. SPSS software, version 23.0 was used for all statistical analysis.

\section{Results}

Over a time period of 3 years, 147 patients with NEC were seen in the department of medical oncology. Out of these, 126 patients were metastatic disease. Twelve patients among these patients did not receive any chemotherapy in view of poor performance status. The clinicopathological profile and the survival analysis were done for 114 patients who satisfied the selection criteria.

This is an open access journal, and articles are distributed under the terms of the Creative Commons Attribution-NonCommercial-ShareAlike 4.0 License, which allows others to remix, tweak, and build upon the work non-commercially, as long as appropriate credit is given and the new creations are licensed under the identical terms.

For reprints contact: reprints@medknow.com

How to cite this article: Lokesh KN, Anand A, Lakshmaiah KC, Babu KG, Lokanatha D, Jacob LA, et al. Clinical profile and treatment outcomes of metastatic neuroendocrine carcinoma: A single institution experience. South Asian J Cancer 2018;7:207-9. 


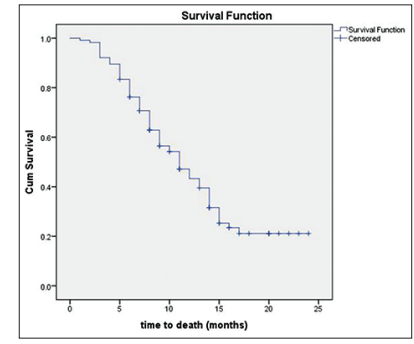

Figure 1: Kaplan-Meier curve for survival of $\mathrm{m}$ neuroendocrine carcinoma patients

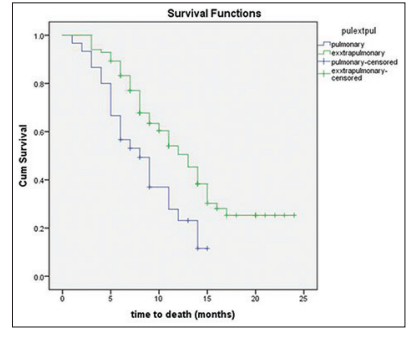

Figure 2: Comparison of survival outcomes for metastatic pulmonary neuroendocrine carcinoma and extrapulmonary neuroendocrine carcinoma

\section{Patient characteristics}

The median age at diagnosis was 55 years (range, 15-78 years). A male preponderance was seen with a male to female ratio being 1.4:1. Gastrointestinal and hepatobiliary tract taken together was the most common site seen in 38 (33\%) patients. Lung was the second most common site seen in $26 \%$, followed by head and neck region (14\%) and genitourinary tract (GUT) (14\%). Three patients had breast as the primary site whereas one had bone-only disease. The most common site of metastasis was liver seen in $65 \%$ of patients. This was followed by bone and lung with the incidence being $54 \%$ and $42 \%$, respectively. Other sites of metastasis included peritoneal cavity, brain, and ovaries. The clinical characteristics have been included in Table 1.

\section{Treatment outcomes}

All patients included in the study received chemotherapy in the form of platinum agents (cisplatin or carboplatin) in combination with etoposide (EP). Patients having bony metastasis also received zoledronic acid along with EP regimen. Partial response was documented in $23.68 \%$, stable disease in $50.87 \%$ whereas progressive disease was seen in $25.43 \%$ of the patients. None of our patients showed a complete response to the EP chemotherapy. The response rate was better in patients with EPNEC when compared to PNEC, although it was statistically not significant $(\mathrm{PR}=27.4$ vs. $13.3, P=0.093)$. The median OS of all 114 patients was 11 months[Figure 1]. According to the primary site, the median OS was 12 months for GIT, 8 months for lung, 13 months for head and neck, 12 months for GUT, and 10 months for the unknown primary. The survival of PNEC was significantly lower than EPNEC ( 8 vs. 13 months; $P=0.003$; Figure 2 ). There was a significant difference in survival based on the level of Ki67\% expression. Those with Ki67 $>55 \%$ had poor outcomes when compared to those having $<55 \%$ (9 vs. 14 months; $P=0.008$ ). In our study, the elevated LDH level was not associated with poor outcomes. There was also no significant association of survival with age and sex [Table 2].

\section{Discussion}

The NEN arises from the cells throughout the neuroendocrine system present diffusely in the body. ${ }^{[1-3]}$ There is a significant increase in the incidence and prevalence of this tumor. ${ }^{[15]}$ The reason for this increase could be the improvement in classification as well as a better diagnostic approach. The most common site of NEN arising from foregut is bronchus (15\%). Stomach, pancreas, jejunum/ileum, and appendix are the common sites in the midgut all of which contribute around 15\%
Table 1: Patient's characteristics $(n=114)$

\begin{tabular}{lc}
\hline & $n(\%)$ \\
\hline Median age, years (range) & $55(15-78)$ \\
$\leq 60$ & $70(61)$ \\
$>60$ & $44(39)$ \\
Sex & \\
Male & $66(58)$ \\
Female & $48(42)$ \\
Site & \\
Pulmonary & $30(26)$ \\
Extrapulmonary & $84(74)$ \\
GIT & $38(33)$ \\
$\quad$ Head and neck & $16(14)$ \\
GUT & $17(15)$ \\
Breast & $3(3)$ \\
Bone only & $1(1)$ \\
$\quad$ Unknown & $10(9)$ \\
Ki-67\% & \\
$\leq 55$ & $64(56)$ \\
$>55$ & $50(44)$ \\
LDH & \\
Normal & $54(47)$ \\
Elevated & $60(53)$ \\
Site of metastasis & \\
Liver & $74(65)$ \\
Bone & $62(54)$ \\
Lung & $49(42)$ \\
Others & $42(37)$ \\
\hline GIT=Gastrointestinal tract, GUT=Genitourinary tract, LDH=Lactate dehydrogenase \\
\end{tabular}

Table 2: Multivariate Cox regression analysis for survival

\begin{tabular}{lccc} 
Parameter & $P$ & HR & $\begin{array}{c}\text { 95\% CI } \\
\text { (lower-upper) }\end{array}$ \\
\hline Age $(\leq 60$ vs. $>60$ years) & 0.078 & 1.561 & $0.951-2.562$ \\
Sex (male vs. female) & 0.977 & 1.007 & $0.623-1.630$ \\
LDH (normal vs. elevated) & 0.374 & 0.804 & $0.496-1.301$ \\
Ki-67 $(\leq 55 \%$ vs. $>55 \%)$ & 0.008 & 0.517 & $0.318-0.840$ \\
\hline
\end{tabular}

$\mathrm{LDH}=$ Lactate dehydrogenase, $\mathrm{CI}=$ Confidence interval, $\mathrm{HR}=$ Hazard ratio

each. In the hindgut, rectum is the common site representing $10 \%$ of all NEN. ${ }^{[16]}$ In our study, the system most commonly involved system was GIT followed by respiratory and genitourinary. Lung was the most common primary site of disease seen in $26 \%$ of patients. The pattern of metastasis in the present study was similar to that reported in most of the studies. ${ }^{[17,18]}$ The only exception was that bony metastasis, which was higher in the present study and seen in 54\% the patients.

The standard treatment of patients of NEC remains platinum-based agent along with EP. This is mostly extrapolated from the results of small cell lung cancer data and major prospective studies in NEC patients are lacking. The treatment outcomes of NEC remain poor. Studies have shown an objective response rate of $27.7 \%-73 \%$ and a median survival ranging from 5.1 to 16.5 months in metastatic PNEC. ${ }^{[19-23]}$ In comparison to PNEC, the outcomes of metastatic EPNEC has been slightly better with a response rate around $30 \%$ and a median survival of 3.5-22 months. ${ }^{[25-28]}$ In the present study, $23.7 \%$ of all patients showed a partial response whereas stable disease was seen in $50.9 \%$.

Progressive disease was documented in $25.4 \%$ of all patients. The response rate was slightly less than Western data which South Asian Journal of Cancer $\bullet$ Volume 7 Issue $3 \bullet$ July-September 2018 
may be due to a different population and biological nature of the disease. The median OS of all patients was 11 months. There was a significant difference in the median OS of metastatic PNEC and EPNEC (8 vs. 13 months; $P=0.003$ ).

Studies have shown an association of the different variable with the survival in patients of NEC, the strongest and consistent association being with Ki67\% level ( $\leq 55 \%$ or $>55 \%) \cdot{ }^{[25,27,28]}$ In the present study as well, the association of Ki67\% with survival was found to be statistically significant $(P=0.007)$. Other variables like age $(<60$ or $>60$ years), sex (male vs. female) and LDH value (normal vs. elevated) did not show any significant association with treatment outcomes.

Although there have been advances in the treatment of NET the outcomes of high-grade metastatic NEC remains dismal.

\section{Conclusion}

NEC is a rare tumor group with poor prognosis. Metastatic NEC of the lung has a worse outcome than metastatic EPNEC. The standard treatment remains platinum in combination with EP which provides a modest survival benefit. There was a definite association of Ki67 level with the outcome of disease while LDH did not seem to have any prognostic implication in our study. There is a need for further studies with other chemotherapeutic and novel agents for achieving better treatment outcomes.

\section{Financial support and sponsorship}

Nil.

\section{Conflicts of interest}

There are no conflicts of interest.

\section{References}

1. Travis WD. Advances in neuroendocrine lung tumors. Ann Oncol 2010;21 Suppl 7:vii65-71.

2. Rekhtman N. Neuroendocrine tumors of the lung: An update. Arch Pathol Lab Med 2010; 134:1628-38.

3. Bertino EM, Confer PD, Colonna JE, Ross P, Otterson GA. Pulmonary neuroendocrine/carcinoid tumors: A review article. Cancer 2009; 115:4434-41.

4. Modlin IM, Shapiro MD, Kidd M. Siegfried oberndorfer: Origins and perspectives of carcinoid tumors. Hum Pathol 2004;35: 1440-51.

5. Taal BG, Visser O. Epidemiology of neuroendocrine tumours. Neuroendocrinology 2004;80 Suppl 1:3-7.

6. Bosman TF, Carneiro F, Hruban R. WHO Classification of Tumours of the Digestive System. $4^{\text {th }}$ ed. Lyon: IARC Press; 2010.

7. Hainsworth JD, Johnson DH, Greco FA. Poorly differentiated neuroendocrine carcinoma of unknown primary site. A newly recognized clinicopathologic entity. Ann Intern Med 1988;109:364-71.

8. Pelley RJ, Bukowski RM. Recent advances in diagnosis and therapy of neuroendocrine tumors of the gastrointestinal tract. Curr Opin Oncol 1997;9:68-74.

9. Moertel CG, Kvols LK, O'Connell MJ, Rubin J. Treatment of neuroendocrine carcinomas with combined etoposide and cisplatin. Evidence of major therapeutic activity in the anaplastic variants of these neoplasms. Cancer 1991;68:227-32

10. Mitry E, Baudin E, Ducreux M, Sabourin JC, Rufié P, Aparicio T, et al. Treatment of poorly differentiated neuroendocrine tumours with etoposide and cisplatin. Br J Cancer 1999;81:1351-5.

11. Strosberg JR, Fine RL, Choi J, Nasir A, Coppola D, Chen DT, et al. First-line chemotherapy with capecitabine and temozolomide in patients with metastatic pancreatic endocrine carcinomas. Cancer 2011;117:268-75.

12. Kouvaraki MA, Ajani JA, Hoff P, Wolff R, Evans DB, Lozano R, et al. Fluorouracil, doxorubicin, and streptozocin in the treatment of patients with locally advanced and metastatic pancreatic endocrine carcinomas. J Clin Oncol 2004;22:4762-71.

13. Moertel CG, Lefkopoulo M, Lipsitz S, Hahn RG, Klaassen D. Streptozocin-doxorubicin, streptozocin-fluorouracil or chlorozotocin in the treatment of advanced islet-cell carcinoma. N Engl J Med 1992;326:519-23.

14. Sun W, Lipsitz S, Catalano P, Mailliard JA, Haller DG; Eastern Cooperative Oncology Group, et al. Phase II/III study of doxorubicin with fluorouracil compared with streptozocin with fluorouracil or dacarbazine in the treatment of advanced carcinoid tumors: Eastern cooperative oncology group study E1281. J Clin Oncol 2005;23:4897-904.

15. Yao JC, Hassan M, Phan A, Dagohoy C, Leary C, Mares JE, et al. One hundred years after "carcinoid": Epidemiology of and prognostic factors for neuroendocrine tumors in 35,825 cases in the United States. J Clin Oncol 2008;26:3063-72.

16. Pape UF, Anlauf M, Pavel M. Neuroendokrine Neoplasien des gastroenteropankreatischen Systems. Gastroenterologie up2date 2011;7:313-42.

17. Terashima T, Morizane C, Hiraoka N, Tsuda H, Tamura T, Shimada Y, et al. Comparison of chemotherapeutic treatment outcomes of advanced extrapulmonary neuroendocrine carcinomas and advanced small-cell lung carcinoma. Neuroendocrinology 2012;96:324-32.

18. Yamaguchi T, Machida N, Morizane C, Kasuga A, Takahashi H, Sudo K, et al. Multicenter retrospective analysis of systemic chemotherapy for advanced neuroendocrine carcinoma of the digestive system. Cancer Sci 2014; 105:1176-81.

19. Fujiwara Y, Sekine I, Tsuta K, Ohe Y, Kunitoh H, Yamamoto N, et al. Effect of platinum combined with irinotecan or paclitaxel against large cell neuroendocrine carcinoma of the lung. Jpn J Clin Oncol 2007;37:482-6.

20. Sun JM, Ahn MJ, Ahn JS, Um SW, Kim H, Kim HK, et al. Chemotherapy for pulmonary large cell neuroendocrine carcinoma: Similar to that for small cell lung cancer or non-small cell lung cancer? Lung Cancer 2012;77:365-70.

21. Le Treut J, Sault MC, Lena H, Souquet PJ, Vergnenegre A, Le Caer H, et al. Multicentre phase II study of cisplatin-etoposide chemotherapy for advanced large-cell neuroendocrine lung carcinoma: The GFPC 0302 study. Ann Oncol 2013;24:1548-52.

22. Niho S, Kenmotsu H, Sekine I, Ishii G, Ishikawa Y, Noguchi M, et al. Combination chemotherapy with irinotecan and cisplatin for large-cell neuroendocrine carcinoma of the lung: A multicenter phase II study. J Thorac Oncol 2013;8:980-4.

23. Yoshida H, Sekine I, Tsuta K, Horinouchi H, Nokihara H, Yamamoto N, et al. Amrubicin monotherapy for patients with previously treated advanced large-cell neuroendocrine carcinoma of the lung. Jpn J Clin Oncol 2011;41:897-901.

24. Welin S, Sorbye H, Sebjornsen S, Knappskog S, Busch C, Oberg K, et al. Clinical effect of temozolomide-based chemotherapy in poorly differentiated endocrine carcinoma after progression on first-line chemotherapy. Cancer 2011;117:4617-22.

25. Sorbye H, Welin S, Langer SW, Vestermark LW, Holt N, Osterlund P, et al. Predictive and prognostic factors for treatment and survival in 305 patients with advanced gastrointestinal neuroendocrine carcinoma (WHO G3): The NORDIC NEC study. Ann Oncol 2013;24:152-60.

26. Hentic O, Hammel P, Couvelard A, Rebours V, Zappa M, Palazzo M, et al. FOLFIRI regimen: An effective second-line chemotherapy after failure of etoposide-platinum combination in patients with neuroendocrine carcinomas grade 3. Endocr Relat Cancer 2012; 19:751-7.

27. Olsen IH, Sørensen JB, Federspiel B, Kjaer A, Hansen CP, Knigge U, et al. Temozolomide as second or third line treatment of patients with neuroendocrine carcinomas. ScientificWorldJournal 2012;2012: 170496.

28. Hadoux J, Malka D, Planchard D, Scoazec JY, Caramella C, Guigay J. Postfirst-line FOLFOX chemotherapy for grade 3 neuroendocrine carcinoma. Endocr Relat Cancer 2015;22:289-98. doi:10.1530/ERC-15-0075 